\title{
0 protagonismo do design e suas contribuições no terceiro setor
}

\author{
Rosangela Canônica (Currículo Lattes) \\ Rita Inês Petrykowski Peixe (Currículo Lattes) \\ Adriane Shibata Santos (Currículo Lattes)
}

\section{INTRODUÇÃO}

Desde muito, o uso do design tende a constituir-se como uma importante ferramenta para a diferenciação e aprimoramento de performances, permitindo ser aplicado a diversos contextos. Por meio dele, é possível que novas estratégias possam ser integradas à proposta de valor de diferentes organizações. Como processo, pode gerar resultados concretos que melhoram a qualidade do trabalho organizacional, visto que seu caráter multidisciplinar e interativo permite o uso da criatividade como capital essencial de planos e ações que conduzem equipes de trabalho a criar respostas positivas a desafios diversos, de maneira colaborativa. 
No contexto do terceiro setor - entendido como aquele que inclui questões de intervenção e melhoria social - as contribuições do design "divergem" das aplicáveis às organizações do segundo setor, por possuírem realidades bem distintas. Como num contexto de terceiro setor, as organizações não objetivam lucro nem apresentam diferencial competitivo, seu uso transpõe a lógica do desenvolvimento de produtos originalmente proposta no âmbito do design, mediando caminhos que contribuam para criar melhores performances institucionais, sobretudo relacionadas às práticas educativas com pessoas inseridas em projetos de geração de trabalho e renda, possibilitando ampliação de conhecimentos e capacidades técnicas a àqueles que detêm menos oportunidades de acesso.

Com esse foco, o presente artigo, sendo parte da dissertação de mestrado intitulada 'Contribuições do design em contexto do terceiro setor', descreve o design como impulsionador de iniciativas para alavancar estratégias diferenciadas de atuação em organizações do terceiro setor. Sobretudo, apresenta métodos que contribuem para mediar a busca pela descoberta de novas performances utilizando o design thinking ${ }^{1}$ como parâmetro capaz de orientar a gestão de novas ideias, métodos e ferramentas de trabalho nos contextos da educação empreendedora.

\section{DESIGN E PERFORMANCE ORGANIZACIONAL}

Qual seria, atualmente, a importância do design na diferenciação de performances organizacionais?

Para Brown (2010), o design não se constitui como uma simples resposta. Sua essência é a chave para perguntas mais assertivas para 
a resolução de problemas mais complexos, gerando alternativas impactantes, sustentáveis e inovadoras. Essa habilidade projeta uma visão profundamente humana para o fazer design, desenvolvendo soluções que tenham significado emocional além do funcional para a vida das pessoas.

Partindo de uma visão mais ampliada, Fontoura (2002) afirma que o design é um vasto campo que envolve e converge para diferentes disciplinas. Portanto, ele pode ser visto como uma atividade, como um processo, ou entendido em termos de resultados tangíveis. Abrange também a função de gestão de projetos, atividade projetual, atividade conceitual, ou ainda como um fenômeno cultural. É tido como um meio para adicionar valor às coisas produzidas pelo homem e também como um veículo para as mudanças sociais e políticas.

De acordo com Mozota (2011), para tornar o design compreensível a quem não é especializado na área, determinados assuntos e questões devem ser considerados. Primeiro, deve-se descrever a natureza da profissão, compreendendo as diversas áreas em que o design é praticado e os vários métodos que os profissionais de design empregam em seu trabalho. A partir desse ponto, é preciso perceber a relevância do design para a ciência da administração, descobrir o que se pode aprender com o processo criativo e, por conseguinte, medir o impacto sobre a performance organizacional a fim de determinar o que se pode auferir com ele. Afinal, o "design é uma atividade fundamental, com ramificações capilares em todas as atividades humanas" (BONSIEPE, 1997, p. 15).

Para Mozota (2011), as técnicas de design conectam o caráter lógico da abordagem científica às dimensões intuitivas e artísticas do trabalho criativo,estabelecendo umelo,complementarefundamental, entre arte e ciência. Seu posicionamento é, portanto, como atividade 
de resolução de problemas, um exercício criativo, sistemático e de coordenação, o que implica dizer que sua aproximação com a gestão se dá pela soma das mesmas características. Para a autora, o designer, devido à sua natureza, inspira a mudança e projeta novas ideias na medida em que as dimensões culturais e imaginativas do design estão fortemente relacionadas a metas institucionais estratégicas, geradas pela visão organizacional e construção de sua identidade corporativa.

De modo geral, o design fala de pessoas e como elas são colocadas no centro dos processos para construir valor com elas e para elas. Nesse sentido, o presente estudo parte da premissa de uma cultura de inovação fundamentada no design como processo de condução de novas performances para organizações do terceiro setor.

Para Pinheiro e Alt (2011), a prática de inserir o design como modelo de gestão se traduz fundamentalmente no resgate de valores essenciais do design e na aplicação desses valores nas estratégias organizacionais, de maneira a fomentar processos sistemáticos de alta relevância e impacto positivo às pessoas. Sua contribuição se baseia em um novo olhar com um enfoque de inovação que valoriza relações interpessoais e traz sentido tanto para os colaboradores da organização quanto para seu público-alvo.

De acordo com Brown (2010), é preciso que haja muito mais pessoas dispostas a ir além da identificação de problemas ou da crítica às ideias que não deram certo e que se dediquem a buscar soluções. Pois, diante dos desafios que se apresentam hoje, cada sujeito pode fazer sua parte, comprometendo-se com a busca de novas oportunidades. Para tais pressupostos, o autor compreende que existem métodos e habilidades desenvolvidos que podem ser usados para a resolução de problemas mais importantes e 
desafiadores. Seus métodos baseiam-se em um pensamento de design que pode ser compartilhado, aprendido e utilizado por qualquer pessoa e aplicado a diferentes cenários. Trata-se de um modelo mental comprometido especificamente em propor soluções, atrelando importantes conceitos, desenvolvido por designers ao longo das muitas décadas da profissão.

Estima-se que muitos problemas fazem parte do dia a dia das organizações que se comprometem com causas sociais. Além de gerir dificuldades relacionadas à situação de exclusão social na qual seu público beneficiado se encontra, como falta de renda que impacta em condições indignas de moradia, fome, violência, entre outras situações de conflito, outros fatores precisam ser considerados: as organizações precisam administrar metas institucionais relacionadas a número de beneficiados, captação de recursos, índices de exposição em mídias, entre outros contextos da gestão organizacional, incluindo o desenvolvimento de estratégias para atingir resultados cada vez mais assertivos ante o público que se propõem atender. Sob esse último aspecto, o design pode vir a contribuir com competências estratégicas para possibilitar melhores resultados, conforme nos aponta Herrero Filho (2011) ao se reportar às disciplinas essenciais à execução de estratégias organizacionais. O autor considera que o design representa uma das mais importantes abordagens para o desenho e redesenho de processos na organização, na medida em que acelera a criação de valor e busca por novas oportunidades de inovação.

Uma respeitável observação advém de Mozota (2011), ao apontar que a inovação pode ser estimulada com o aumento de conhecimento sobre a natureza da solução de problemas criativos na organização. Isso ocorre na medida em que uma maior consciência sobre as formas de tratamento de problemas gera percepções 
para novas abordagens. Esse entendimento aplicado ao contexto do terceiro setor projeta que novos caminhos podem ser traçados, não apenas para atingir êxito nos resultados, mas, principalmente, sobrevivência.

\section{O MODELO MENTAL DO DESIGN THINKING}

Para Vianna et al. (2012), foi buscando novos caminhos para a inovação que se criou o que hoje é conhecido como "design thinking", uma abordagem que se refere à maneira do designer pensar. Tal pensamento foca, essencialmente, no ser humano, que vê na multidisciplinaridade colaboração e tangibilização de pensamentos e processos, caminhos que conduzem a soluções inovadoras. Pois, ao desafiar os padrões de pensamento, comportamentos e de sentimentos, os "design thinkers" produzem soluções que geram novos significados e que estimulam os diversos aspectos (cognitivo, emocional e sensorial) abarcados na experiência humana.

Deacordo com Herrero Filho (2011), o design thinking representa uma das mais importantes ferramentas de inovação, pois explica como os procedimentos internos estão integrados à estratégia organizacional. Assim, aplicando seu conceito às disciplinas da execução das estratégias organizacionais, contribui-se, e muito, para se superar níveis de insatisfação, bem como para melhorar a forma de como os processos internos e externos são conduzidos. É importante ressaltar que o design thinking é uma metodologia que possibilita imaginar estados futuros à visão de uma organização, acelerar a inovação e superar problemas de uma forma criativa.

Brown (2010) assegura que o design thinking constitui-se como uma abordagem à descoberta de fazer algo novo, eficiente e amplamente acessível. Seus pressupostos integram todos os 
aspectos da organização em sinergia com a sociedade, permitindo que equipes possam gerar colaborativamente ideias que sejam implementadas. Além disso, os princípios do design thinking podem ser aplicáveis a uma ampla variedade de organizações, não estando atrelados somente a empresas em busca de novos produtos a oferecer.

No contexto do terceiro setor, é possível eleger e aplicar o design thinking na organização por seus pressupostos criativos, dinâmicos e colaborativos, que contribuem para que as equipes possam identificar e compreender problemáticas vivenciadas dentro da própria estrutura organizacional, carentes por novas estratégias. Diante disso, torna-se presumível avaliar e aplicar mediações orientadas pelo design thinking para o desenvolvimento de modelos de atuação mais pontuais que favoreçam práticas diárias, de modo a mediar oportunidades para melhoria dos processos relacionados à educação empreendedora.

O design thinking se beneficia da capacidade que todos têm para a resolução de problemas, buscando libertar a criatividade. Para chegar a esse ponto, contudo, há um percurso mental a seguir, dividido em fases, conforme a Figura 1:

Figura 1 - Representação das fases do processo de design thinking

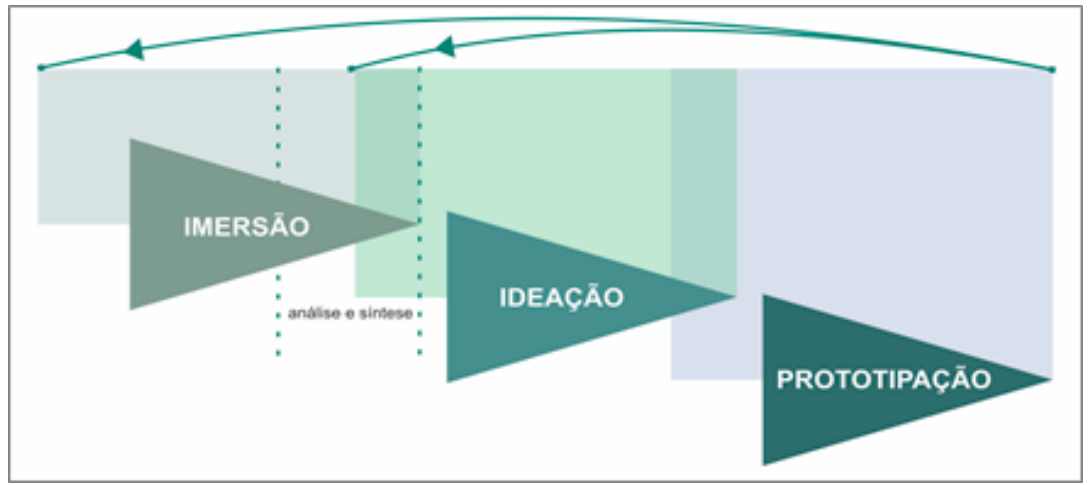

Fonte: primária, baseada em Vianna et al. (2012) 
Todavia, é importante observar, conforme ponderam Vianna et al. (2012), que as etapas que compõem o modelo mental do design thinking não são lineares, pois possuem uma natureza bastante versátil e não linear. Ou seja, tais fases podem ser configuradas de acordo com a necessidade e natureza do problema em questão.

A fase de imersão, na qual há uma aproximação com o contexto do problema, pode ser dividida em duas etapas: preliminar e em profundidade. A primeira fase tem como objetivo o entendimento inicial do problema, enquanto quea segunda destina-seà identificação de oportunidades que irão nortear a geração de soluções durante as fases seguintes; a análise e síntese das informações coletadas durante a fase de imersão têm a finalidade de identificar insights², organizá-los de maneira a obter-se padrões e a criar desafios que auxiliam na compreensão do problema; a fase de ideação tem como intuito gerar ideias inovadoras para o tema do projeto, e, para isso, utilizam-se as ferramentas de síntese criadas na fase de análise para estimular a criatividade e gerar soluções que estejam de acordo com o contexto do assunto trabalhado. Por isso, a fase de prototipação tem como função auxiliar a validação das ideias geradas e, apesar de ser apresentada como uma das últimas fases do processo de design thinking, pode ocorrer ao longo do projeto em paralelo com a imersão e a ideação (VIANNA et al., 2012).

Para cada fase prevista no modelo mental do design thinking há ferramentas que auxiliam diferentes pessoas a utilizarem seus pressupostos para a resolução de problemas, conforme demonstrado no Quadro 1:

2 É o achado proveniente da imersão' a identificação de uma ou mais oportunidades (VIANNA et al., 2012). 
Quadro 1 - Ferramentas que compõem as fases do design thinking

\begin{tabular}{|c|c|c|}
\hline FASE & FERRAMENTA & DESCRIÇÃO \\
\hline \multirow{8}{*}{ Imersão } & Reenquadramento & $\begin{array}{l}\text { Examina problemas ou questões não resolvidas } \\
\text { sob diferentes perspectivas e diversos ângulos. } \\
\text { Assim, desconstrói crenças e suposições } \\
\text { dos atores e, ao quebrar seus padrões de } \\
\text { pensamento, ajuda-os a mudar paradigmas, } \\
\text { impulsionando-os a dar o primeiro passo para } \\
\text { alcançar soluções inovadoras. }\end{array}$ \\
\hline & $\begin{array}{l}\text { Pesquisa } \\
\text { exploratória }\end{array}$ & $\begin{array}{l}\text { Auxilia no entendimento do contexto a ser } \\
\text { trabalhado e fornece insumos para a definição } \\
\text { de demandas e necessidades latentes. }\end{array}$ \\
\hline & Pesquisa desk & $\begin{array}{l}\text { Busca de informações sobre o tema do projeto } \\
\text { em fontes diversas (websites, livros, revistas, } \\
\text { artigos etc.). }\end{array}$ \\
\hline & Entrevistas & $\begin{array}{l}\text { Método de procura direta. As informações } \\
\text { buscadas permeiam o assunto pesquisado e os } \\
\text { temas centrais da vida dos entrevistados. }\end{array}$ \\
\hline & $\begin{array}{l}\text { Cadernos de } \\
\text { sensibilização }\end{array}$ & $\begin{array}{l}\text { Forma de obter informações sobre as pessoas e } \\
\text { seus universos, com o mínimo de interferência } \\
\text { sobre suas ações, ou quando a questão } \\
\text { investigada se desenrola de forma intermitente } \\
\text { ou dentro de um longo período. }\end{array}$ \\
\hline & $\begin{array}{l}\text { Sessões } \\
\text { generativas }\end{array}$ & $\begin{array}{l}\text { Possibilita o encontro com os atores envolvidos } \\
\text { no tema do projeto, para que dividam suas } \\
\text { experiências e realizem juntos atividades nas } \\
\text { quais expõem suas visões sobre os temas do } \\
\text { projeto. Visa, portanto, entender o que sabem, } \\
\text { sentem e sonham, muitas vezes de maneira } \\
\text { tática e latente. }\end{array}$ \\
\hline & Um dia na vida & $\begin{array}{l}\text { É uma simulação, por parte do pesquisador, } \\
\text { da vida de uma pessoa ou situação estudada. } \\
\text { Ou seja, vivencia-se uma situação por um } \\
\text { determinado tempo com objetivo de agir sob } \\
\text { um diferente ponto de vista, interagindo com } \\
\text { os contextos das pessoas com as quais se estaria } \\
\text { confrontando no dia a dia. }\end{array}$ \\
\hline & Sombra & $\begin{array}{l}\text { É o acompanhamento da situação a ser } \\
\text { analisada, com objetivo de entender como a } \\
\text { pessoa se relaciona com o contexto do tema } \\
\text { estudado, que tipo de artefatos e atores estão } \\
\text { envolvidos, quais emoções, expectativas e } \\
\text { hábitos. Assim, identificam-se oportunidades e } \\
\text { necessidades latentes. }\end{array}$ \\
\hline
\end{tabular}

(continua) 
Quadro 1 - Ferramentas que compõem as fases do design thinking (continuação)

\begin{tabular}{|c|c|c|}
\hline FASE & FERRAMENTA & DESCRIÇÃO \\
\hline \multirow{8}{*}{$\begin{array}{l}\text { Análise e } \\
\text { síntese }\end{array}$} & Cartões de insights & $\begin{array}{l}\text { São reflexões embasadas em dados reais } \\
\text { das pesquisas de imersão, transformadas em } \\
\text { cartões que facilitam a rápida consulta e o seu } \\
\text { manuseio. }\end{array}$ \\
\hline & $\begin{array}{l}\text { Diagrama de } \\
\text { afinidades }\end{array}$ & $\begin{array}{l}\text { É uma organização e agrupamento dos cartões } \\
\text { de insights com base em afinidade, similaridade, } \\
\text { dependência ou proximidade, gerando um } \\
\text { diagrama que contém as macroáreas que } \\
\text { delimitam o tema trabalhado, suas subdivisões } \\
\text { e interdependências. }\end{array}$ \\
\hline & Mapa conceitual & $\begin{array}{l}\text { Permite a visualização gráfica, construída para } \\
\text { simplificar e organizar visualmente dados } \\
\text { complexos de campo, em diferentes níveis de } \\
\text { profundidade e abstração. Ilustra os elos entre } \\
\text { os dados e permite que novos significados sejam } \\
\text { extraídos das informações levantadas nas etapas } \\
\text { iniciais da fase de imersão, principalmente a } \\
\text { partir das associações entre elas. }\end{array}$ \\
\hline & $\begin{array}{c}\text { Critérios } \\
\text { norteadores }\end{array}$ & $\begin{array}{l}\text { São diretrizes balizadoras para o projeto, } \\
\text { evidenciando aspectos que não devem ser } \\
\text { perdidos de vista ao longo de todas as etapas } \\
\text { do desenvolvimento das soluções. Surgem da } \\
\text { análise dos dados coletados. Servem como base } \\
\text { para a determinação dos limites do projeto e do } \\
\text { seu verdadeiro propósito. }\end{array}$ \\
\hline & Personas & $\begin{array}{l}\text { São arquétipos, personagens ficcionais, } \\
\text { concebidos a partir da síntese de } \\
\text { comportamentosobservados entre pessoascom } \\
\text { perfis extremos. Representam as motivações, } \\
\text { desejos, expectativas e necessidades, reunindo } \\
\text { características significativas de um grupo mais } \\
\text { abrangente. }\end{array}$ \\
\hline & Mapa da empatia & $\begin{array}{l}\text { Ferramenta de síntese das informações } \\
\text { sobre o público-alvo numa visualização do } \\
\text { que ele diz, faz, pensa e sente. Possibilita a } \\
\text { organização de dados da fase de imersão de } \\
\text { forma a prever entendimento de situações de } \\
\text { contexto, comportamentos, preocupaçóes e até } \\
\text { aspirações dos atores estudados. }\end{array}$ \\
\hline & Jornada do usuário & $\begin{array}{l}\text { É uma representação gráfica que segue } \\
\text { descrevendo os principais passos percorridos } \\
\text { pelo usuário, durante e depois da aquisição e } \\
\text { utilização de algum bem ou serviço. }\end{array}$ \\
\hline & Blueprint & $\begin{array}{l}\text { É uma matriz que representa visualmente, } \\
\text { de forma esquemática e simples, o complexo } \\
\text { sistema de interação que caracterizam uma } \\
\text { prestação de serviços. }\end{array}$ \\
\hline
\end{tabular}

(continua) 
Quadro 1 - Ferramentas que compõem as fases do design thinking (continuação)

\begin{tabular}{|c|c|c|}
\hline FASE & FERRAMENTA & DESCRIÇÃO \\
\hline \multirow{4}{*}{ Ideação } & Brainstorming & $\begin{array}{l}\text { Técnica para estimular a geração de um } \\
\text { grande número de ideias em um curto espaço } \\
\text { de tempo. Geralmente realizado em grupo, } \\
\text { mediado por um moderador, responsável por } \\
\text { deixar os participantes à vontade e estimular } \\
\text { a criatividade sem deixar que o grupo perca o } \\
\text { foco. }\end{array}$ \\
\hline & $\begin{array}{l}\text { Workshop de } \\
\text { cocriação }\end{array}$ & $\begin{array}{l}\text { Encontro organizado na forma de uma série de } \\
\text { atividades em grupo com objetivo de estimular } \\
\text { a criatividade e a colaboração, fomentando a } \\
\text { criação de soluções inovadoras. }\end{array}$ \\
\hline & Cardápio de ideias & $\begin{array}{l}\text { Representa um catálogo de todas as ideias } \\
\text { geradas no projeto. Pode incluir comentários } \\
\text { relativos às ideias, eventuais desdobramentos e } \\
\text { oportunidades de interesse. }\end{array}$ \\
\hline & $\begin{array}{c}\text { Matriz de } \\
\text { posicionamento }\end{array}$ & $\begin{array}{l}\text { Ferramenta de análise estratégica das ideias } \\
\text { geradas, utilizada na validação destas em } \\
\text { relação aos critérios norteadores, bem como às } \\
\text { necessidades das personas criadas no projeto. O } \\
\text { objetivo desse recurso é apoiar o processo de } \\
\text { decisão, a partir da comunicação eficiente dos } \\
\text { benefícios de cada solução, de modo que as } \\
\text { ideias mais estratégicas sejam selecionadas para } \\
\text { serem prototipadas. }\end{array}$ \\
\hline \multirow{5}{*}{ Prototipação } & $\begin{array}{l}\text { Protótipo em } \\
\text { papel }\end{array}$ & $\begin{array}{l}\text { São representações de interfaces gráficas com } \\
\text { diferentes níveis de fidelidade. Como o próprio } \\
\text { nome sugere, o resultado será em papel. }\end{array}$ \\
\hline & Modelo de volume & $\begin{array}{l}\text { São representações de ideias em níveis de } \\
\text { fidelidade. Desde baixa - com poucos detalhes } \\
\text { - até alta, com a aparência final. }\end{array}$ \\
\hline & Encenação & $\begin{array}{l}\text { É a simulação improvisada de uma situação, que } \\
\text { pode representar diferentes intenções. }\end{array}$ \\
\hline & Storyboard & $\begin{array}{l}\text { É a representação visual de uma história por } \\
\text { meio de quadros estáticos, compostos por } \\
\text { desenhos, colagens, fotografias ou qualquer } \\
\text { outra técnica disponível. }\end{array}$ \\
\hline & $\begin{array}{l}\text { Protótipo de } \\
\text { serviços }\end{array}$ & $\begin{array}{l}\text { É a simulação de artefatos materiais, ambientais } \\
\text { ou relaçôes interpessoais que representam } \\
\text { um ou mais aspectos de um serviço, de forma } \\
\text { a envolver o usuário e simular a prestação da } \\
\text { solução proposta. }\end{array}$ \\
\hline
\end{tabular}

Fonte: primária, baseado em Vianna et al. (2012)

3 Refere-se a qualquer ato de criatividade coletiva (compartilhado por duas ou mais pessoas) (VIANNA et al., 2012). 
Esse modelo mental reúne as habilidades e características que os designers têm aprendido e desenvolvido ao longo de décadas e representa um próximo passo, que é "colocar essas ferramentas nas mãos de pessoas que talvez nunca tenham pensado em si mesmas como designers e aplicá-las a uma variedade muito mais ampla de problemas" (BROWN, 2010, p. 3).

Uma maneira de contribuir para o design thinking se incorporar por toda uma organização é fazer com que as pessoas participem da experiência. Isso leva a crer que para o design thinking se difundir no terceiro setor será necessário possibilitar às pessoas que atuam nas organizações experimentar seu poder, aplicando-o às suas práticas diárias. Isso significa que, a partir de seus pressupostos, seja possível vislumbrar a superação de desafios e fomentar uma cultura baseada no entusiasmo.

Ainda para Brown (2010), uma atitude de experimentação diz respeito a uma atmosfera de otimismo. Sem o otimismo - a crença inalterável de que as coisas poderiam ser melhores do que são - a disposição de experimentar será continuamente frustrante. Portanto, indivíduos, equipes e organizações inteiras, para colher o poder do design thinking, precisam cultivar o otimismo, pois as pessoas precisam acreditar que têm o poder de criar novas ideias e proposições que atenderão a necessidades não satisfeitas e que terão impacto positivo.

Entre as muitas características que distinguem as práticas do design thinking, está o fato dessa metodologia possibilitar às equipes de trabalho uma ampla compreensão acerca das mais variadas soluções que pretendem identificar. A criatividade impulsionada por suas práticas, conectada ao seu pensamento visual, permite às pessoas a visualização de dados de maneira rápida e holística. Sobretudo, o exercício representa o universo do tema pesquisado, 
colocando em evidência os achados e insights que circunscrevem as ações do projeto, favorecendo principalmente a colaboração da equipe. Esse estímulo para a colaboração por meio de uma visualização permite a estruturação e correlação de dados, além da elaboração de desafios a serem alcançados no projeto a ser proposto. Assim, Brown (2010) considera que palavras e números têm sua utilidade, mas só a representação visual pode, simultaneamente, relevar tanto as características funcionais de uma ideia quanto seu conteúdo emocional.

As práticas visuais permitem uma atitude de experimentação, mantendo abertas novas possibilidades, novos direcionamentos e a disposição de novas soluções. Essas práticas relacionadas aos interesses internos da organização de terceiro setor podem contribuir para o envolvimento e o comprometimento de toda equipe nos processos de atuação, de modo que seus profissionais possam colaborar com conhecimentos e ideias de maneira holística sobre métodos aplicados.

Ainda, no design thinking as práticas visuais são constantes e colaboram para que a fruição aconteça em todo o processo. A Figura 2 representa as técnicas de trabalho utilizadas em diferentes fases para que o estímulo criativo advenha e seja considerado, desde a etapa de imersão até a prototipação. Além disso, é importante enfatizar que os instrumentos utilizados contribuem para uma comunicação visual simples, eficaz e compreensível para expressar ideias. 
Figura 2 - Representação dos processos de trabalho utilizados no design thinking

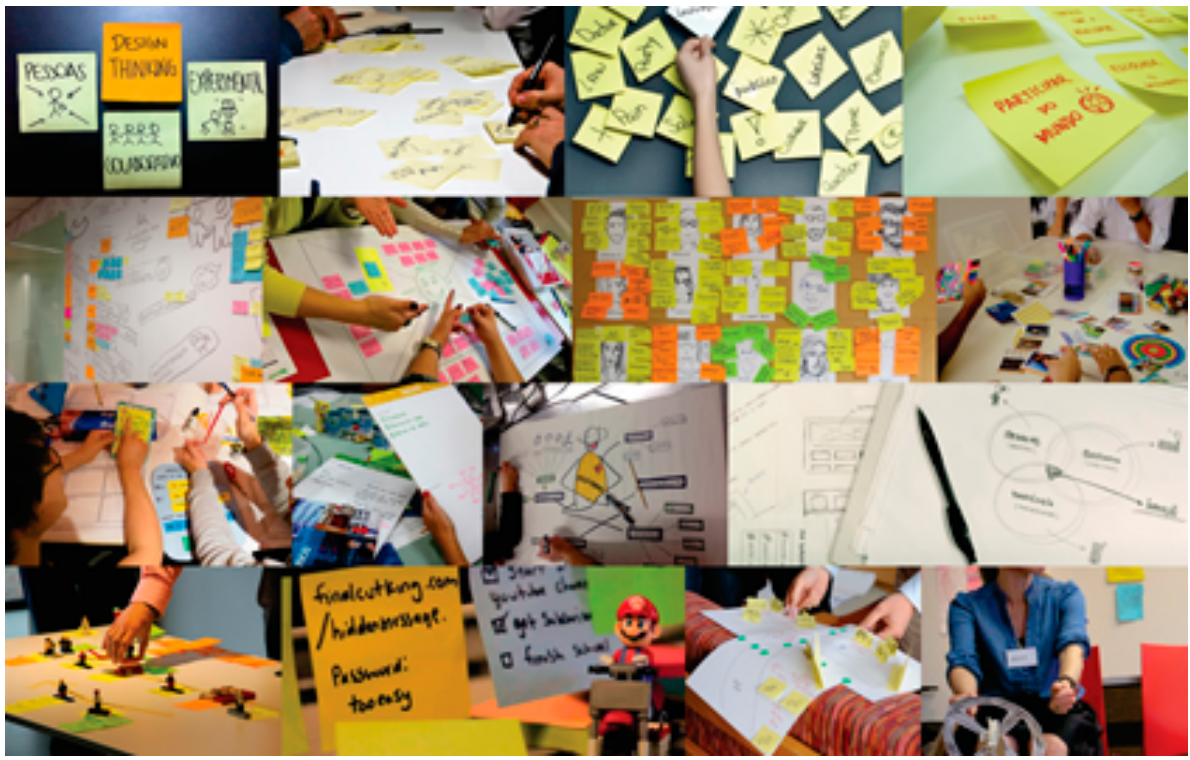

Fonte: primária

Esse direcionamento para a condução de processos de trabalho aplica-se a um ambiente de busca por mudanças. Assegura, essencialmente, que a criatividade individual e coletiva encontre condições de gerar ideias que contribuam para escolhas mais assertivas da organização.

\section{USO DO DESIGN THINKING NA EDUCAÇÃO EMPREENDEDORA: POSSIBILIDADES PARA O TERCEIRO SETOR}

Os pressupostos do Educador Paulo Freire4, acerca de uma educação libertadora, dialógica e socialmente produtiva, compõem os pilares de trabalho das organizações do terceiro setor. Isso

4Educador brasileiro, considerado um dos pensadores mais notáveis no contexto da pedagogia mundial. Destacou-se por seu trabalho na área da educação popular, tanto para a escolarização quanto para a formação da consciência política. 
possibilita que os agentes envolvidos nos processos de inclusão social pelo trabalho vivenciem uma educação socialmente produtiva, combinando desafio e criatividade, o que reflete em mudanças e atitudes, bem como um maior envolvimento e dedicação entre todos para solução de problemas complexos.

Mesmo que não evidenciada, é perceptível a presença do educador Paulo Freire também nos processos de design thinking, tanto no que se refere à adoção de ferramentas de trabalho quanto na abordagem de espaços compartilhados. Tal sinergia enfatiza a importância da autonomia do indivíduo em seus processos, ratificada pelo diálogo e conscientização, os quais propõem ações de colaboração.

É importante considerar que no design social essa relação pode ser mais perceptível, sobretudo por incorporar, além de projetos materiais com resultados tangíveis, ações de ensino e aprendizagem determinantes para o empoderamento de comunidades. Diante de tais questões, as abordagens pedagógicas aplicadas têm como propósito estabelecer bases colaborativas com a responsabilidade de inclusão, mediando a aprendizagem e promovendo a troca de saberes. Tais princípios metodológicos colaborativos favorecem a participação e o envolvimento entre todos os comprometidos nos processos de transformação social.

As práticas participativas (comuns nos pressupostos do design) se fazem presentes nas relações de ensino e aprendizagem ao incluírem diferentes pessoas, trazendo para a negociação múltiplos aspectos de uma mesma situação, pois sustentam a experiência na vivência real da situação, de modo que os agentes envolvidos no processo possam contribuir com seus diferentes saberes para solução de problemas comuns. Como os interesses e vivências são diferenciados para cada pessoa, a negociação torna-se um momento 
no qual uma rica totalidade de visões pode convergir para uma relação dialógica de mudança.

Para Fiori (1987), a pedagogia freireana pensa e pratica um método pedagógico que procura dar ao ser humano a oportunidade de (re)descobrir-se por meio da retomada reflexiva do próprio processo em que vai se descobrindo, se manifestando e se configurando - "método de conscientização". Assim, a consciência do mundo e a consciência de si crescem juntas e em razão direta, sendo uma a luz interior da outra, uma comprometida com a outra. Evidencia-se a intrínseca correlação entre conquistar-se, fazer-se mais si mesmo e conquistar o mundo, fazê-lo mais humano. Mas ninguém se conscientiza separadamente dos demais, esse deve ser um ato coletivo.

Esse conjunto de pressupostos aproxima-se do design thinking, na medida em que tem como foco, essencialmente, o ser humano com vistas à construção de caminhos que conduzem a novas práticas. Aliás, seu escopo metodológico evidencia oportunidades de novas performances nas relações de ensino e aprendizagem, pois o design não considera o conhecimento como transferência de informações (conhecimento como substância). Ele tem uma nova visão de conhecimento como processo de construção coletiva que objetiva o aprender fazendo (aprendizagem cognitiva), a fim de propiciar um contexto para conversações e para a construção social do conhecimento (MOZOTA, 2011).

Entre as muitas contribuições do design thinking aplicado a organizações que buscam a inovação, há uma correlação voltada à educação, em especial aos educadores, de modo a permitir que eles possam construir descobertas sólidas que criam soluções significativas para o atendimento das necessidades relativas ao universo do ensino. Todavia, será que esse mesmo pensamento de 
design não poderia ir ao encontro do atendimento das necessidades de ensino e aprendizagem relativas ao terceiro setor, auxiliando organizações a desenvolverem novas experiências relacionadas a seus métodos?

Para Gonsales et al. (2014), o design thinking possibilita descobrir caminhos sobre o que é "inovação" na prática, prospectando ao universo da educação novas abordagens que visam solucionar problemas e desafios cotidianos de forma colaborativa. No contexto da escola, os educadores estão usando os processos, métodos e ferramentas aprendidos para gerar ideias para suas salas de aula e escolas.

O projeto Design Thinking For Educators, da IDEO (escritório de design global que usa uma abordagem humanística para ajudar organizações dos setores públicos e privados a inovar e crescer), foi dedicado às causas da área da educação, com vistas a contribuir com o empoderamento de educadores diante de problemas complexos. A dedicação a esse projeto gerou a publicação de um roteiro para compartilhamento da metodologia do Design sob uma perspectiva compreensível às pessoas, que podem vir a utilizar seus métodos para superarem, fase a fase, diferentes desafios. De acordo com Gonsales et al. (2014), essa abordagem demanda as seguintes fases (Figura 3):

Figura 3 - Fases do processo "design thinking para educadores".

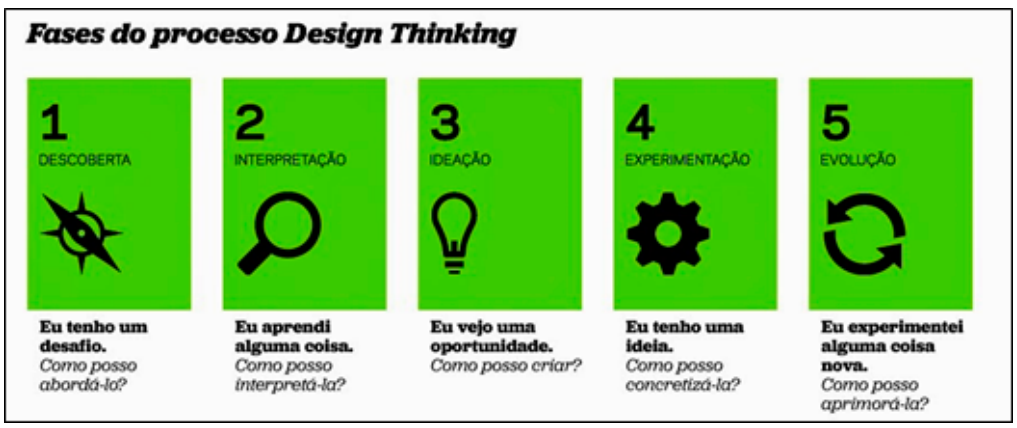

Fonte: Gonsales et al. (2014) 
Esse modelo mental envolve as mesmas fases e ferramentas do design thinking, comentadas no Quadro 1. Porém, pelo fato de seu plano de fundo perpassar o universo das relações de ensino e aprendizagem, cada fase prevista foi idealizada para facilitar a autogestão do educador que se propõe a utilizar seus pressupostos para a resolução colaborativa de problemas, seguindo um percurso essencial para a obtenção de resultados.

Uma importante contribuição do design noâmbito da educação, extensiva ao terceiro setor, refere-se às suas próprias características de aplicar uma abordagem humanística que coloca o ser humano no centro de seus processos. Suas práticas participativas desenvolvem o senso de coletividade, colaboração e da exploração de novas possibilidades e desafios humanos, sobretudo, da experimentação da criatividade como processo de ensino e aprendizagem.

O trabalho das organizações do terceiro setor que atuam com práticas de ensino eaprendizagem com projetos sociais ancora também o complexo percurso de construção do empoderamento de pessoas, incluindo a autoestima, a assunção de responsabilidade consigo próprias e com o coletivo. De acordo com Giannella (2013), essa prática tem chances de ser construída de forma mais sólida e eficaz quando se recorre a processos relacionados à "pedagogia da criatividade". Assim, na medida em que as organizações do terceiro setor atuam mediadas por um processo educativo que faça uso das inteligências múltiplas e, especificamente, das capacidades criativas, expressivas e reflexivas do sujeito, como seu suporte, serão atingidos resultados mais tangíveis e significativos. Pois, a partir de recursos criativos possíveis como a música, canto, dança, desenho e a encenação, tanto teatral quanto performática, da realidade vivenciada-imaginada ou apreendida-, os sujeitos reafirmam sua existência no mundo, vislumbram novas formas de atuação nele, criando novas possibilidades diante os desafios. 
Com base em vivências e pesquisas em curso, pode-se dizer que as experiências no âmbito do terceiro setor também necessitam incluir o Design para que novas metodologias mais convincentes, abrangentes e atraentes possam ser criadas, contribuindo para a reflexão e o desenvolvimento do espírito crítico das pessoas em processo da descoberta empreendedora e, principalmente, para a construção de conhecimento tácito, intuitivo e contínuo de mudança.

Outro ponto relevante para se incluir o design nos caminhos do terceiro setor é colocado por Mozota (2011) quando afirma que o design, por não considerar o conhecimento como informação, mas concepção, o gerencia de modo pró-ativo, de forma que os conhecimentos gerados são utilizados e reutilizados e não armazenados. Nesse sentido, as organizações que acreditam na criatividade e na construção do conhecimento tornam-se, eminentemente, receptivas ao design.

De acordo com Freedman (2003 apud PORTUGAL, 2013), aquilo que as pessoas chegam a saber e como chegam a saber deve romper as fronteiras tradicionais. Enquanto os limites da educação se ampliam e se transformam, as pessoas cada vez mais passam a aprender a partir de formas visuais. Essa importante característica de aprendizagem visual cria espaço para uma educação a partir do design.

Para Portugal (2013), as relações de ensino vêm passando por inúmeras transformações, uma vez que a cultura visual, dada a sua relevância no contexto de aprendizagem, tem sido tema de interesse recente no meio destinado à educação, ainda sujeita a muitas transformações e carente de colaborações, tanto de ordem prática quanto teórica. Por esse motivo, o design como área relacionada à cultura visual é convidado a fazer parte de experiências que possibilitam ampliação dos processos de ensino e aprendizagem, 
incorporando abordagens mais criativas, colaborativas e significativas. Sob esse aspecto, o design thinking se apresenta ao terceiro setor como um importante recurso, passível de inspirar organizações a criarem abordagens que rompam com modelos tradicionais, construindo novos modelos para inovar no âmbito social e multiplicar conhecimentos.

\section{CONSIDERAÇÕES FINAIS}

A pesquisa de mestrado 'Contribuições do design em contexto do terceiro setor' apresentou a possibilidade de se incorporar abordagens voltadas a novas performances de trabalho no terceiro setor por meio do design thinking. Para isso foram investigadas algumas das definições sobre inovação, cujo sentido refere-se ao ato de "fazer algo novo ou renovar", considerando os meios plausíveis para alcançar resultados a partir do design como processo de mediação.

Com ênfase em uma organização tida como estudo de caso, foi possível pensar a diferenciação de performances de trabalho a partir do modelo mental do design, compreendendo sua importância como capital intelectual. A ponderação dessa forma de pensar, de agir e de criar novas possibilidades ao terceiro setor incluiu técnicas e ferramentas de design - dinâmicas e pontuais - na descoberta de melhores oportunidades voltadas à educação empreendedora, tornando-a mais estratégica e eficaz.

Possibilitar o contato do terceiro setor com o modelo mental utilizado por designers para gerar novas ideias levou a organização investigada a reavaliar sua metodologia vinculada à educação empreendedora, de modo a aperfeiçoar processos e incluir melhorias que atendem suas necessidades, tanto internas quanto externas. 
Em decorrência, a experiência demonstrou que é possível utilizar ferramentas de design para enriquecer processos de ensino no contexto social. O conhecimento e uso de tais ferramentas permite aperfeiçoar metodologias e conduzir práticas educativas, tornando a educação empreendedora mais efetiva e próxima da realidade social envolvida. 


\section{REFERÊNCIAS}

BONSIEPE, G. Design do material ao digital. Florianópolis: FIESC/ IEL, 1997.

BROWN, T. Design thinking: uma poderosa metodologia para decretar o fim das velhas ideias. Rio de Janeiro: Elsevier, 2010.

FIORI, E. M. Prefácio. In: Paulo Freire. Pedagogia do oprimido. 17. ed. Rio de Janeiro, Paz e Terra, 1987.

FONTOURA, A. M. Educação de crianças e jovens através do design. 2002. 337 p. Tese (Doutorado em Engenharia de Produção) Universidade Federal de Santa Catarina, Florianópolis, 2002.

GIANNELLA, V. Pedagogia da criatividade: percursos de arte educação no empoderamento de sujeitos para a gestão social integrativa. Revista Interdisciplinar de Gestão Social, 2013.

GONSALES, P. Design thinking para educadores. Instituto Educadigital, 2014. Disponível em: <http://www.dtparaeducadores. org.br> Acesso em: 15 mar. 2014.

HERRERO FILHO, E. Pessoas focadas na estratégia: as disciplinas da execução da estratégia. Rio de Janeiro: Elsevier, 2011.

MOZOTA, B. Borja de. Gestão do Design: usando o design para construir valor de marca e inovação corporativa. Porto Alegre: Bookman, 2011.

PINHEIRO, T. ALT, L. Design thinking Brasil: empatia, colaboração e experimentação para pessoas, negócios e sociedade. Rio de Janeiro: Elsevier, 2011.

PORTUGAL, C. Design, educação e tecnologia. Rio de Janeiro: Rio Books, 2013. 
VIANNA, M. Design thinking: inovação em negócios. Rio de Janeiro: MJV Press, 2012. 
